\title{
Dye Sensitization and Local Surface Plasmon Resonance Enhanced Upconversion Luminescence for Efficient \\ Perovskite Solar Cells
}

Wenbo Bi $i^{a}$, Yanjie $\mathrm{Wu}^{a}$, Cong Chen ${ }^{a}$, Donglei Zhou ${ }^{a}$, Zonglong Song ${ }^{a}$, Deyang $\mathrm{Li}^{b}$, Guanying Chen ${ }^{b}$, Qilin Dai ${ }^{c}$, Yongsheng Zhu ${ }^{d}$ and Hongwei Song ${ }^{* a}$

${ }^{a}$ State Key Laboratory on Integrated Optoelectronics, College of Electronic Science and Engineering, Jilin University, 2699 Qianjin Street, Changchun, 130012, People's Republic of China.

E-mail: songhw@jlu.edu.cn

${ }^{\mathrm{b}}$ MIIT Key Laboratory of Critical Materials Technology for New Energy Conversion and Storage, School of Chemistry and Chemical Engineering \& Key Laboratory of Micro-systems and Micro-structures, Ministry of Education, Harbin Institute of Technology, Harbin 150001, China. ${ }^{\mathrm{c}}$ Department of Chemistry, Physics, and Atmospheric Sciences, Jackson State University, Jackson, Mississippi 39217, USA.

${ }^{\mathrm{d} C o l l e g e}$ of Physics and Electronic Engineering, Nanyang Normal University, Nanyang 473061, People's Republic of China. 


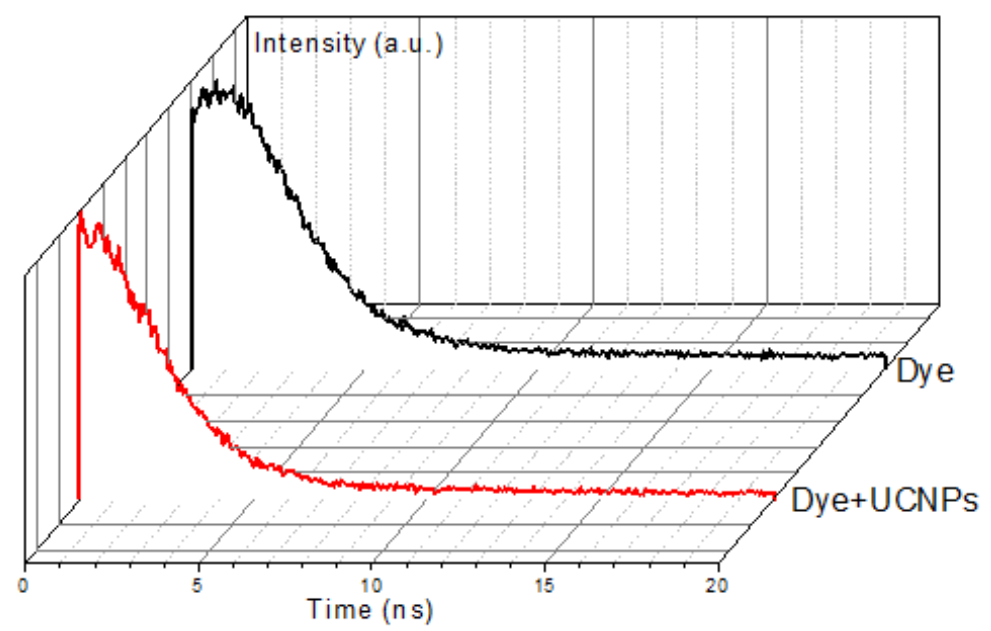

Figure S1 Fluorescence lifetime curves of dye with and without UCNPs.
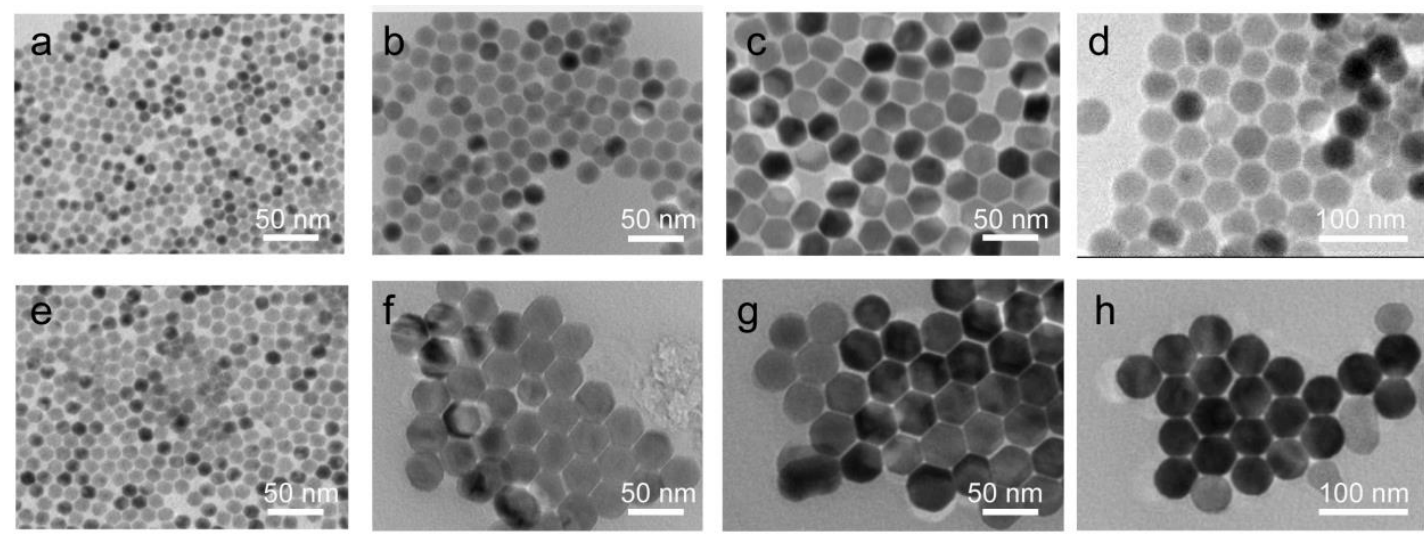

Figure S2 a-h) TEM images of the core and core/shell UCNPs with different size.
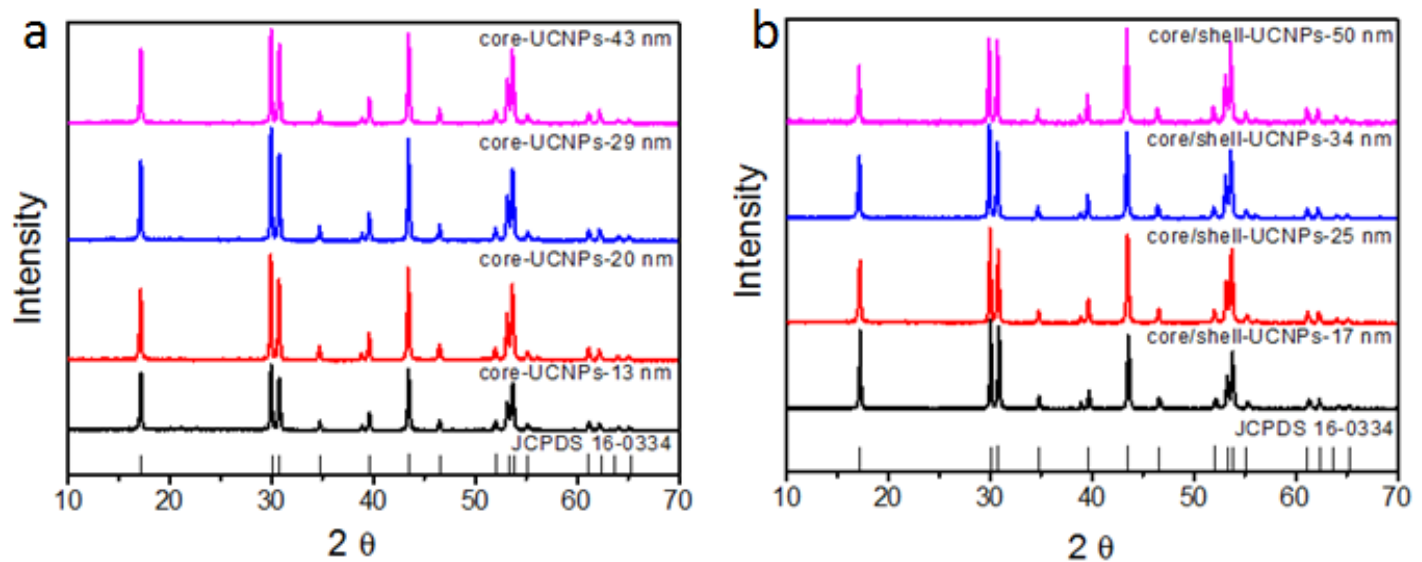

Figure S3 XRD patterns for different size of a) core UCNPs and b) core/shell UCNPs. 


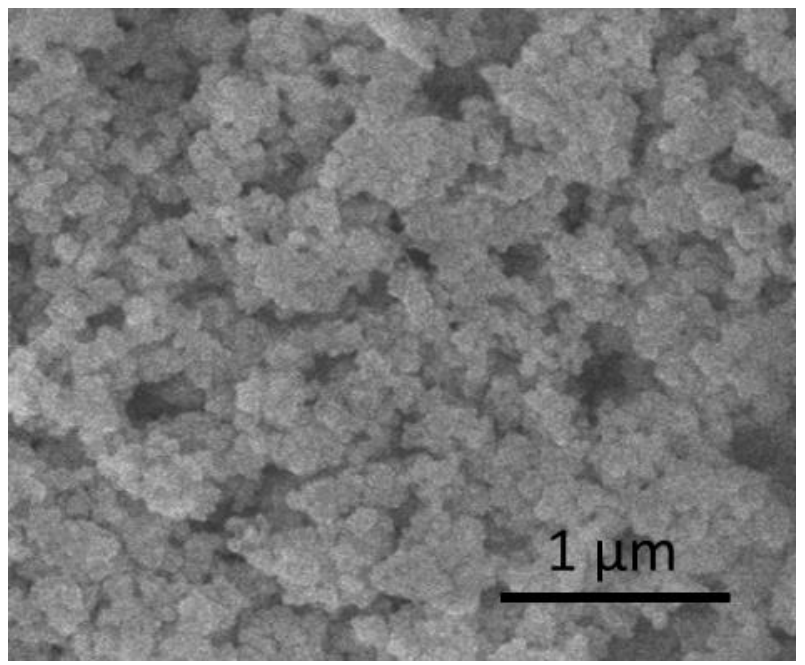

Figure S4 SEM image of UCNPs spin coated on the $\mathrm{SnO}_{2}$ film.

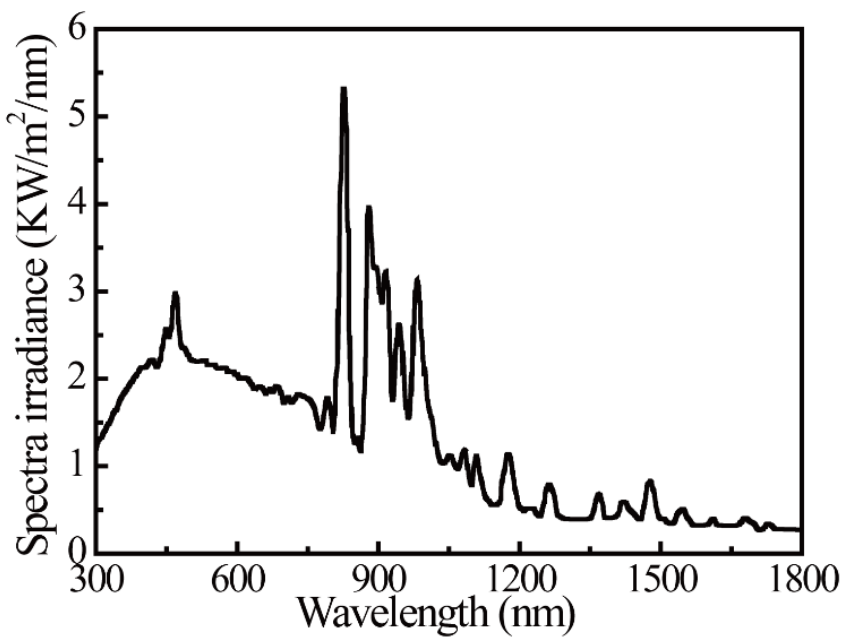

Figure S5 The light spectra of our solar simulator (150 W Xenon lamp). 

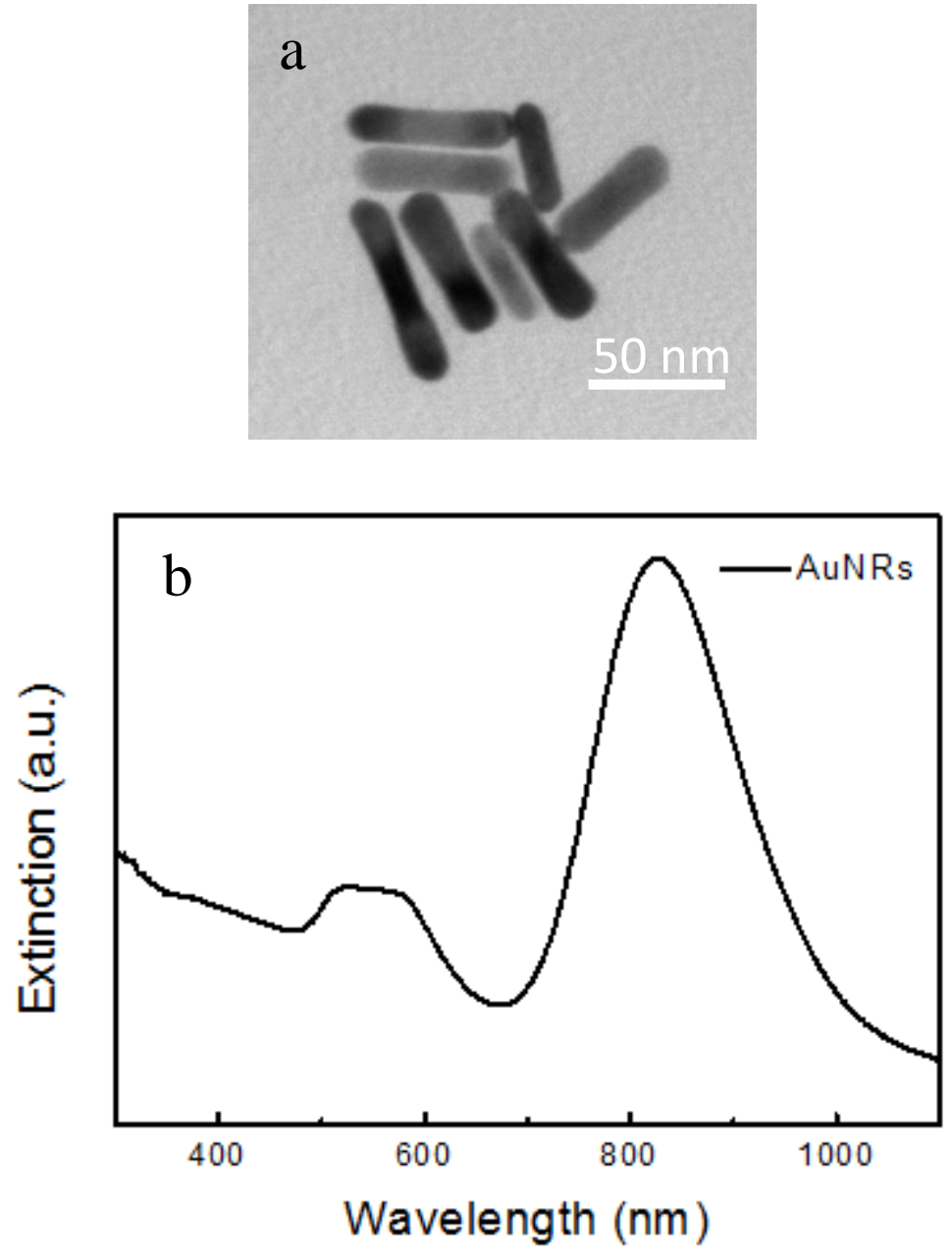

Figure S6 a) TEM image of AuNRs. b) Extinction spectra of the AuNRs in ethanol solution.

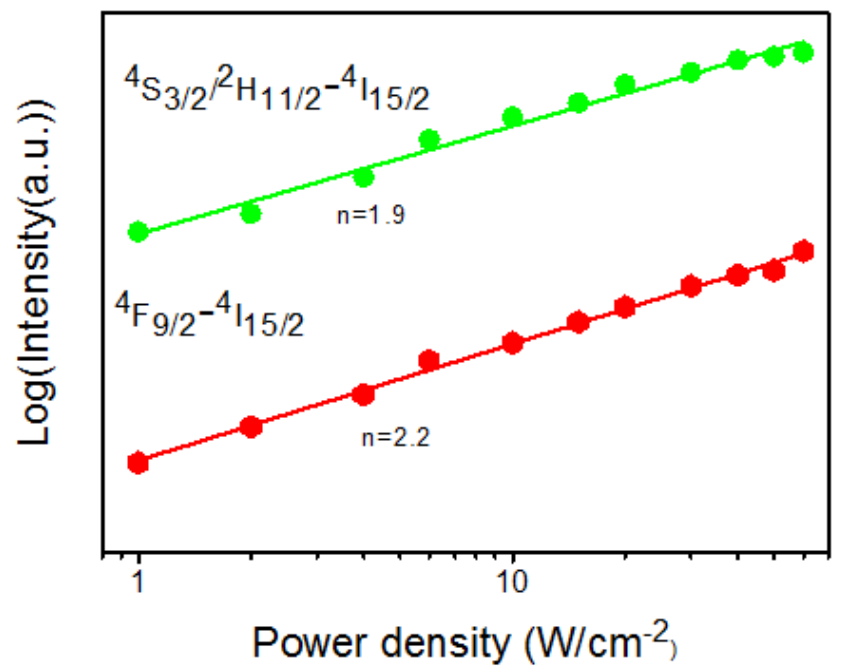

Figure S7 The power density dependence of UCL intensity (green and red emissions) for UCNPs/IR-783 dye/AuNRs composite film under $808 \mathrm{~nm}$ excitation. 


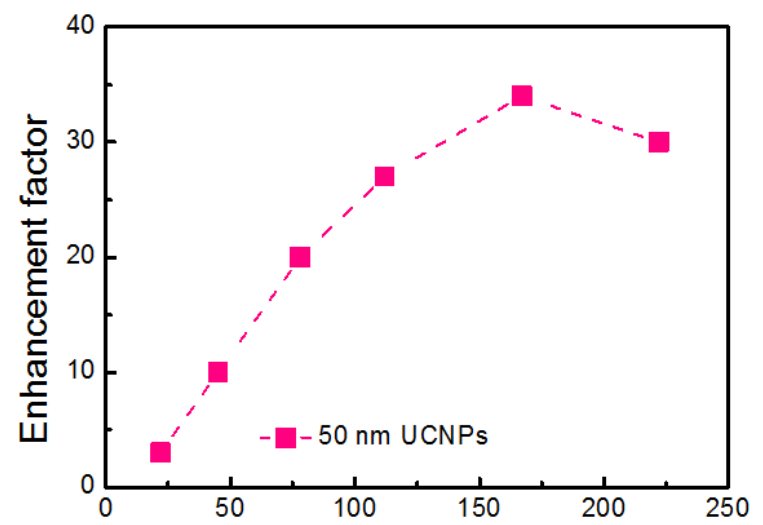

IR-783 dye numbers per UCNPs

Figure S8 Dependence of the enhancement factor from IR-783 dye numbers per UCNPs.
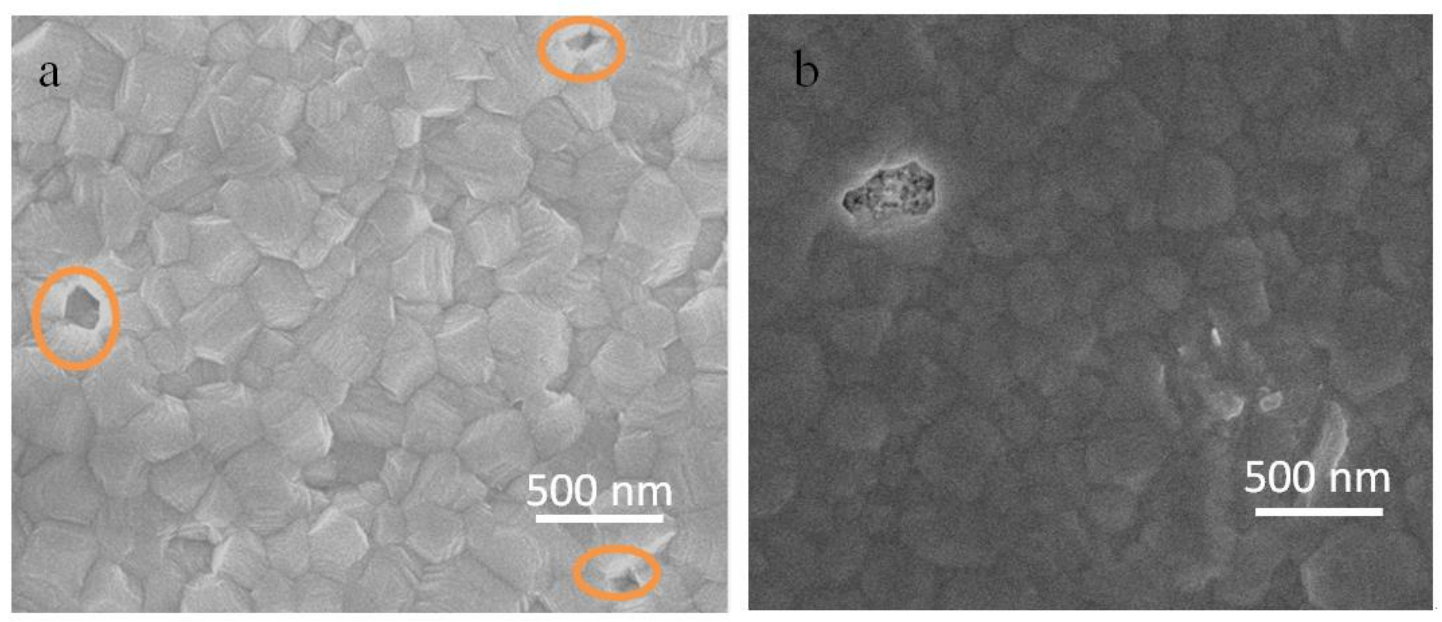

Figure S9 a) SEM image of perovskite layer of control device. b) SEM image of perovskite film deposited on $\mathrm{SnO}_{2} /$ AunRs.
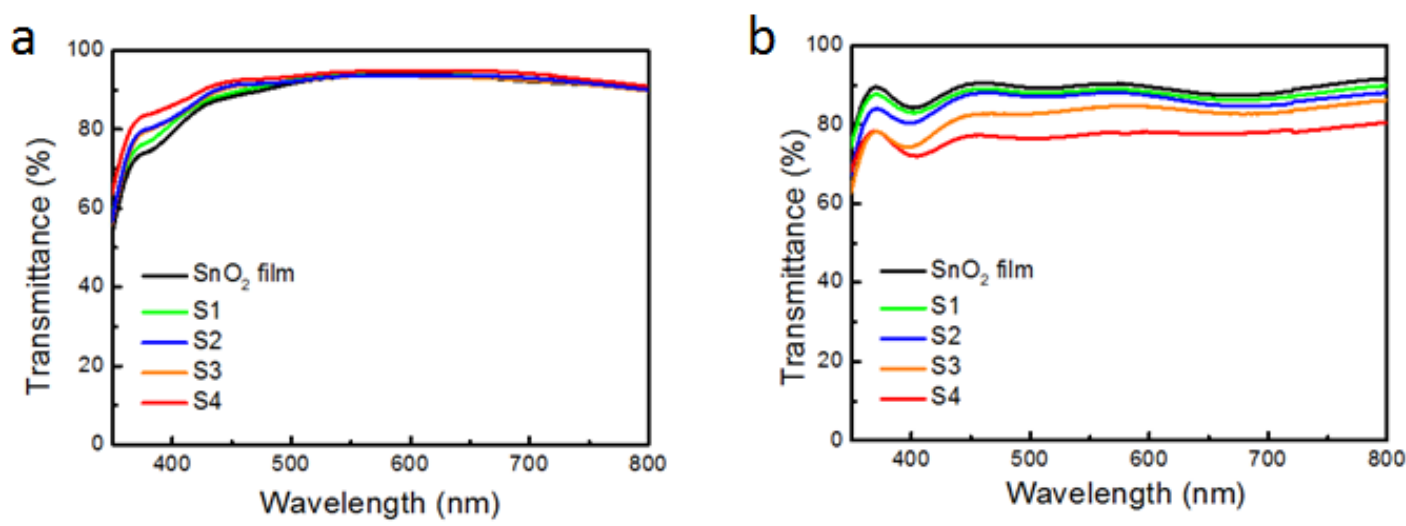

Figure S10 a) TT and b) VT spectra for $\mathrm{SnO}_{2}$ film with different size of UCNPs. 


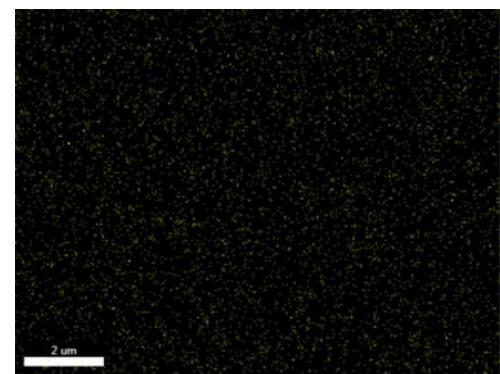

Figure S11 EDX Au element mapping of UCNPs/IR-783 dye/AuNRs film.
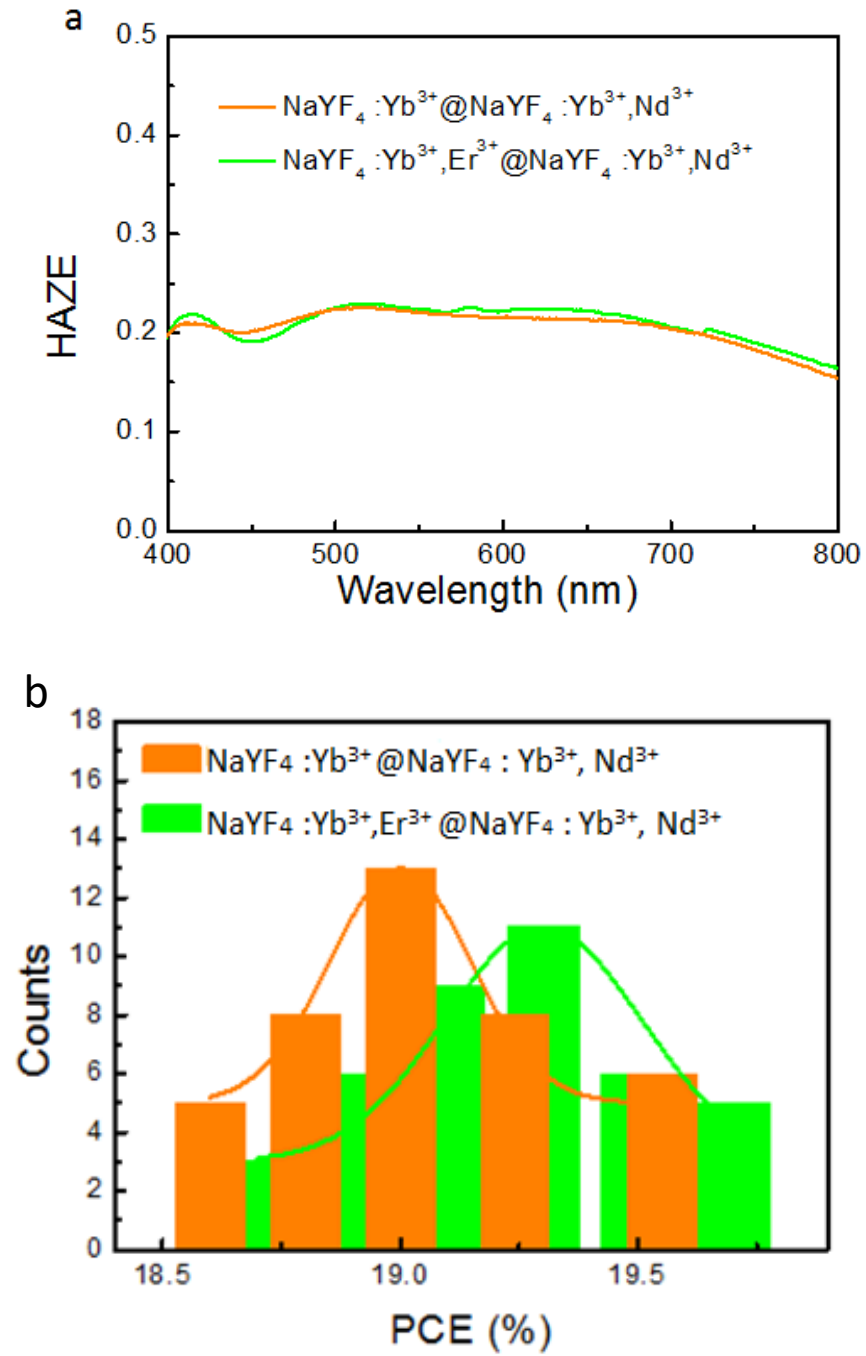

Figure S12 a) HAZE factor for two kinds of films. b) Statistical PCEs of 40 devices for core/shell $\mathrm{NaYF}_{4}$ with or without $\mathrm{Er}^{3+}$. 


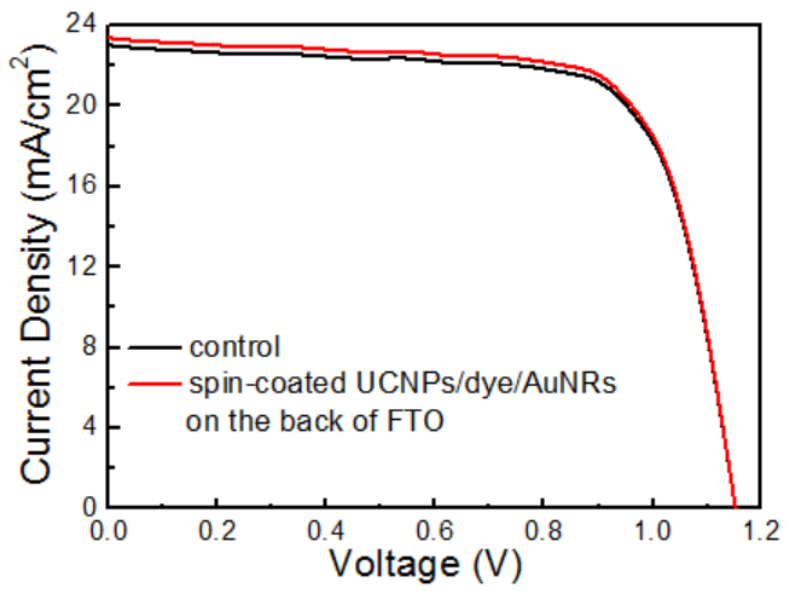

Figure S13 J-V curves of PSCs for control and spin-coated UCNPs/IR-783 dye/AuNRs on the back of FTO.
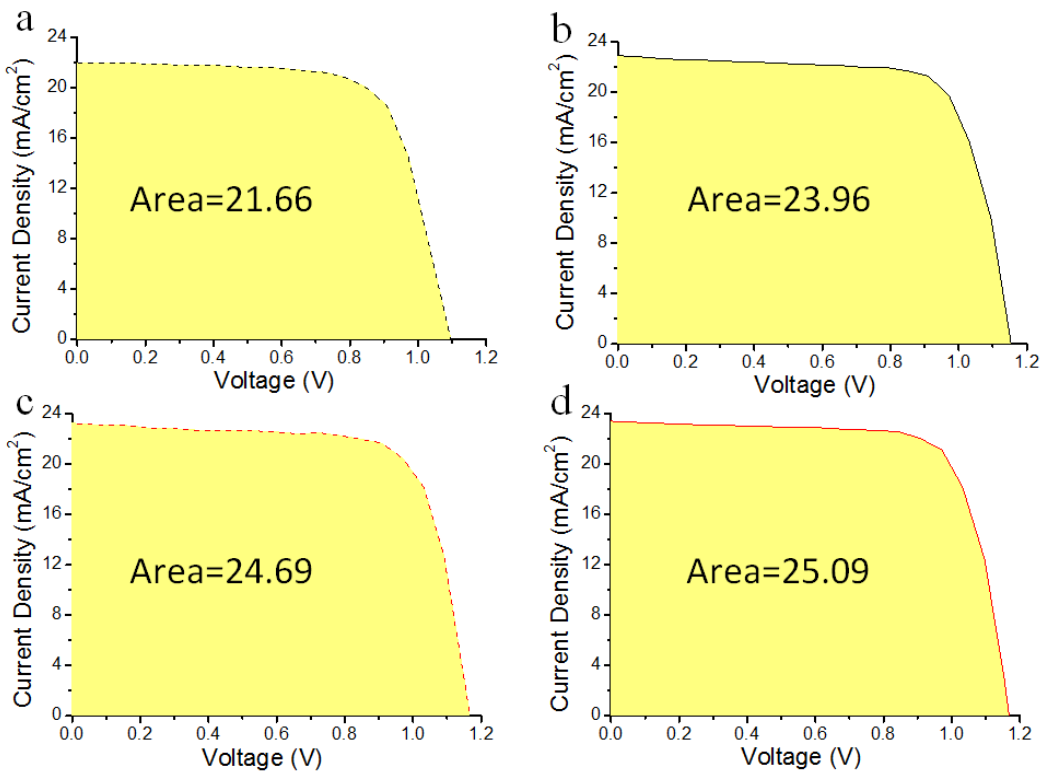

Figure S14 Hysteresis behaviors from J-V curves under different scan directions were measured for devices with and without incorporate UCNPs/IR-783 dye/AuNRs composite film. The integral areas are used to calculate HIs. (a) Forward scan and (b) reverse scan for control devices, (c) forward scan and (d) reverse scan for the UCNPs/IR-783 dye/AuNRs modified devices. 


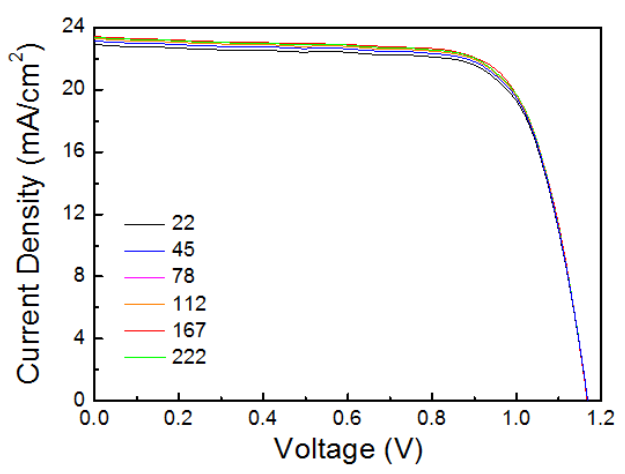

Figure S15 J-V curves for introduced UCNPs with different dye numbers to PSCs.
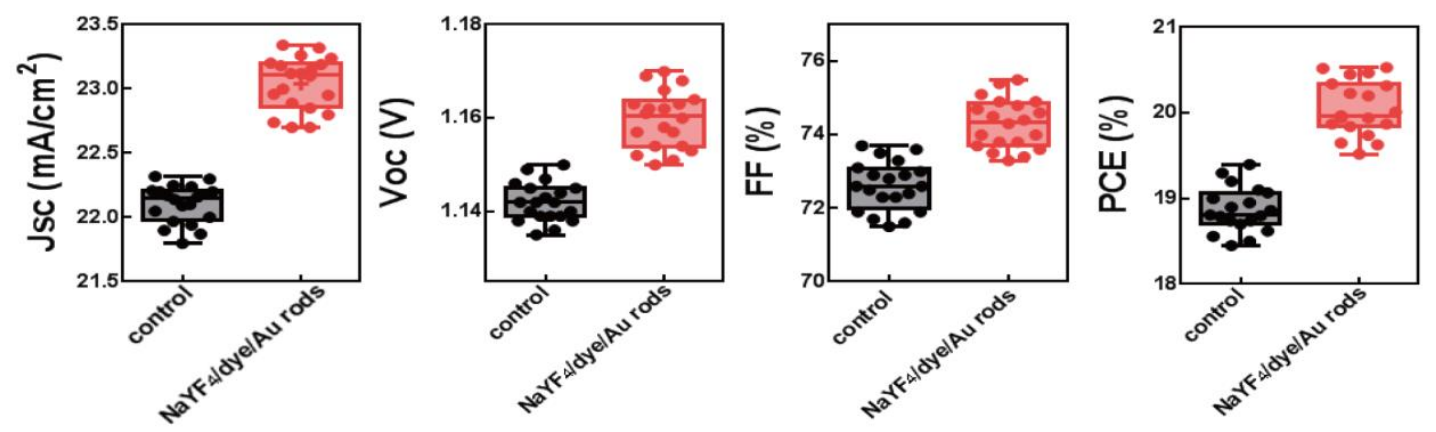

Figure S16 Jsc, Voc, FF, and PCE parameters of 20 PSC devices for with and without UCNPs/IR-783 dye/AuNRs composite film.

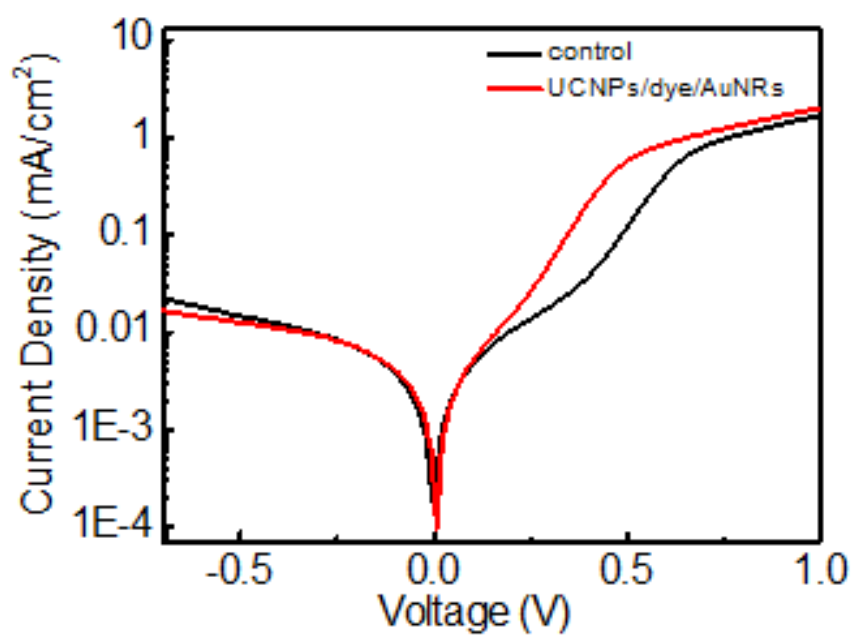

Figure S17 Dark J-V curves of the devices for control and incorporated UCNPs/IR-783 dye/AuNRs composite film. 


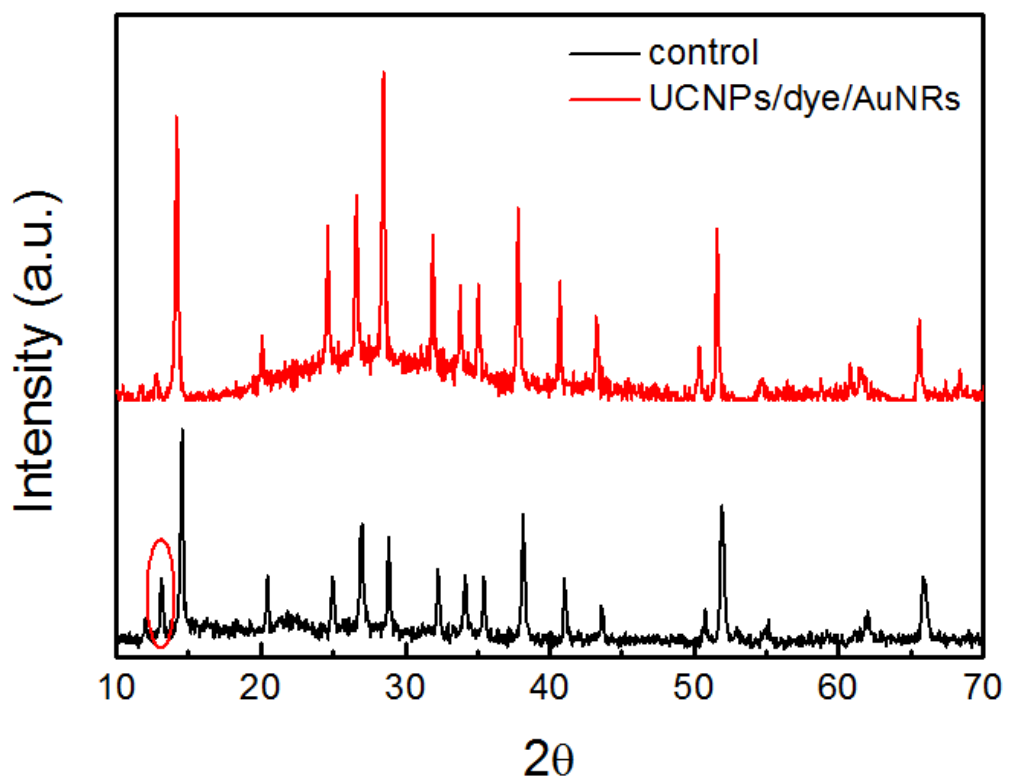

Figure S18 XRD patterns of control device and incorporate UCNPs/IR-783 dye/AuNRs film device after $500 \mathrm{~h}$ storage. 
Table S1 Lifetime of $\mathrm{Er}^{3+}$ dependence on UCNPs of different particle sizes and different dye concentrations.

\begin{tabular}{|l|l|l|l|l|l|}
\hline UCNPs size & & & & & \\
\hline $17 \mathrm{~nm}$ & & & & & \\
\hline $25 \mathrm{~nm}$ & $342 \mu \mathrm{s}$ & $345 \mu \mathrm{s}$ & $349 \mu \mathrm{s}$ & $353 \mu \mathrm{s}$ & $360 \mu \mathrm{s}$ \\
\hline $34 \mathrm{~nm}$ & $348 \mu \mathrm{s}$ & $352 \mu \mathrm{s}$ & $358 \mu \mathrm{s}$ & $365 \mu \mathrm{s}$ & $372 \mu \mathrm{s}$ \\
\hline $50 \mathrm{~nm}$ & $360 \mu \mathrm{s}$ & $364 \mu \mathrm{s}$ & $369 \mu \mathrm{s}$ & $375 \mu \mathrm{s}$ & $386 \mu \mathrm{s}$ \\
\hline
\end{tabular}

Table S2 Photovoltaic parameters of 40 PSCs spin coated with various concentrations of AuNRs.

\begin{tabular}{|c|r|r|r|r|}
\hline Au rods concentrations & PCE $(\%)$ & $\mathrm{Jsc}\left(\mathrm{mA} / \mathrm{cm}^{2}\right)$ & Voc $(\mathrm{V})$ & FF $(\%)$ \\
\hline $1.0 \mathrm{wt} \%$ & 20.24 & 23.26 & 1.167 & 74.55 \\
\hline $1.5 \mathrm{wt} \%$ & 20.40 & 23.37 & 1.169 & 74.62 \\
\hline $2.0 \mathrm{wt} \%$ & 20.50 & 23.50 & 1.170 & 74.61 \\
\hline $3.0 \mathrm{wt} \%$ & 20.25 & 23.23 & 1.169 & 74.58 \\
\hline
\end{tabular}

Table S3 Summary of application of upconversion materials in PSCs.

\begin{tabular}{|c|c|c|c|c|}
\hline Upconversion materials & Application mode & $\begin{array}{l}\operatorname{PCE}(\%) \\
(\mathrm{AM} 1.5 \mathrm{G})\end{array}$ & $\begin{array}{l}\operatorname{PCE}(\%) \\
\text { (high power } \\
\text { irradiation) }\end{array}$ & Ref. \\
\hline$\beta-\mathrm{NaYF}_{4}: \mathrm{Yb}^{3+}, \mathrm{Er}^{3+}$ & Mesoporous layer & 17.8 & - & 12 \\
\hline$\beta-\mathrm{NaYF}_{4}: \mathrm{Yb}^{3+}, \mathrm{Er}^{3+}$ & Mesoporous layer & 16 & - & 14 \\
\hline $\mathrm{TiO}_{2}: \mathrm{Yb}^{3+}, \mathrm{Er}^{3+}$ & Mesoporous layer & 13.4 & - & 10 \\
\hline$\beta-\mathrm{NaYF}_{4}: \mathrm{Yb}^{3+}, \mathrm{Tm}^{3+} @ \mathrm{NaYF}_{4}$ & Mesoporous layer & 16.9 & - & 32 \\
\hline $\mathrm{LiYF}_{4}: \mathrm{Yb}^{3+}, \mathrm{Er}^{3+}$ & $\begin{array}{l}\text { External (at the } \\
\text { reverse of FTO) }\end{array}$ & 11 & 11.87 & 9 \\
\hline $\mathrm{mCu}_{2-\mathrm{x}} \mathrm{S} @ \mathrm{SiO}_{2} @ \mathrm{Er}_{2} \mathrm{O}_{3}$ & Mesoporous layer & 17.8 & 18.8 & 33 \\
\hline $\begin{array}{l}\mathrm{NaYF}_{4}: \mathrm{Yb}^{3+}, \mathrm{Er}^{3+} / \mathrm{NaYF}_{4}: \mathrm{Yb}^{3+}, \\
\mathrm{Tm}^{3+} / \mathrm{Ag}\end{array}$ & $\begin{array}{l}\text { External (behind } \\
\text { the transparent } \\
\text { electrode) }\end{array}$ & 16.9 & 19.2 & 7 \\
\hline $\mathrm{NaYF}_{4}: \mathrm{Yb}^{3+}, \mathrm{Er}^{3+} @$ & Mesoporous layer & 20.5 & 21.1 & This \\
\hline $\begin{array}{l}\mathrm{NaYF}_{4}: \mathrm{Yb}^{3+}, \mathrm{Nd}^{3+} / \mathrm{IR}-783 \\
\text { dye/AuNRs composite film }\end{array}$ & & & & work \\
\hline
\end{tabular}




\section{Molecular weight estimate of UCNPs, number of IR-783 dye per UCNPs.}

Molecular weight of the core-shell UCNPs:

For a hexagonal phase $\mathrm{NaYF}_{4}$ unit cell, the parameters are a=b=5.96 $\mathrm{A}, \mathrm{c}=3.53 \AA$. The density of hexagonal phase $\mathrm{NaYF}_{4}$ is $4.23 \mathrm{~g} / \mathrm{cm}^{3}$. The diameter (d) of prepared core shell UCNPs are 17, 25, 34 and $50 \mathrm{~nm}$. Take $17 \mathrm{~nm}$ UCNPs as an example, and the molecular weight can be calculated as follows:

The volume of UCNPs is

$V_{U C N P S}=\frac{4}{3} \pi\left(\frac{\mathrm{d}}{2}\right)^{3}=4 / 3 * 3.14 *(17 / 2)^{3}=2571 \mathrm{~nm}^{3}$

The average mass of UCNPs is

$m_{U C N P S}=\rho_{U C N P S} \cdot \mathrm{V}_{U C N P S}=4.23 * 10^{-21} * 2571=1.088 * 10^{-17} \mathrm{~g}$

The molecular weight of UCNPs is

$M_{U C N P S}=\mathrm{m}_{U C N P S} \cdot N_{A}=1.088 * 10^{-17} * 6.02 * 10^{23}=6.55^{*} 10^{6} \mathrm{~g} / \mathrm{mol}$

The mass of UCNPs used was $10 \mathrm{mg}$ in each sample. So the number of UCNPs in each sample is

$N_{U C N P S}=0.01 / 6.55 * 10^{6}=0.655 \mathrm{nmol}$

At the optimal concentration, the number of dye molecules in each sample is

$N_{d y e}=7.5^{*} 10^{-6} / 750=10 \mathrm{nmol}$

The number of dye per UCNPs is

$N_{\text {dye } / \text { UCNPs }}=10 / 0.655=15$

Based on the above calculations, the number of dye molecules attached to UCNPs with particle sizes of 25, 34 and $50 \mathrm{~nm}$ can be obtained, which are 24, 53 and 167 . 


\section{Device Fabrication}

Firstly, the anode of FTO substrate was etched with zinc powder and 37\% hydrochloric acid, and then the etched FTO substrate was immersed in deionized water, ethanol, isopropyl alcohol and acetone for 15 minutes. The washed FTO substrate was blow-dried with nitrogen, treated with UV-ozone for 30 minutes. The colloidal dispersion of $\mathrm{SnO}_{2}$ (Alfa Aesar, $15 \%$ in $\mathrm{H}_{2} \mathrm{O}$ colloidal dispersion) was diluted with ultra-pure water $\left(\mathrm{SnO}_{2}: \mathrm{H}_{2} \mathrm{O}=1: 1(\mathrm{v}: \mathrm{v})\right)$, then was spin-coated onto FTO substrates at $5000 \mathrm{rpm}$ for $30 \mathrm{~s}$, and then transfer to a hot plate annealed in ambient air at $150{ }^{\circ} \mathrm{C}$ for 30 minutes. After $\mathrm{FTO} / \mathrm{SnO}_{2}$ substrates temperature drops to room temperature, $\mathrm{Au}$ rods solution with a concentration of 2 wt \% with $\mathrm{SnO}_{2}$ colloidal dispersion is used for spin-coating at $2000 \mathrm{rpm}$ for $30 \mathrm{~s}$. After the solution is dried, the concentration is used for $5 \mathrm{mg} / \mathrm{ml}$ dye connected $\mathrm{NaYF}_{4}$ in DMF solution, was spun over at a rate of 4,000 rpm for $30 \mathrm{~s}$. The precursor of perovskite were $73.4 \mathrm{mg} \mathrm{PbBr}_{2}$, $507.1 \mathrm{mg}$ of $\mathrm{PbI}_{2}, 22.4 \mathrm{mg}$ of $\mathrm{MABr}$ and $172 \mathrm{mg}$ of FAI dissolved in $1 \mathrm{ml}$ of $\mathrm{DMF}: \mathrm{DMSO}=4: 1(\mathrm{v}: \mathrm{v})$ solution, and $40 \mu \mathrm{L}$ of CsI with a concentration of $1.5 \mathrm{M}$ were added. The perovskite precursor solution was rotated on the base prepared before by one-step method, with the speed of $500 \mathrm{rpm}$ for $6 \mathrm{~s}$ and $4000 \mathrm{rpm}$ for $40 \mathrm{~s}$ respectively, and the anti-solvent ether was added at the last $25 \mathrm{~s}$. The spinner is then annealed at $150{ }^{\circ} \mathrm{C}$ for 15 minutes in a glove box. Then add $72.3 \mathrm{mg}$ of spiro-OMeTAD, $22.5 \mu \mathrm{L}$ of 4-tert-butylpyridine, And $22.5 \mu \mathrm{L}$ of acetonitrile solution containing $170 \mathrm{mg} / \mathrm{mL}$ of lithium bis-(trifluoromethylsulfonyl) imide in $1 \mathrm{~mL}$ of chlorobenzene was spun-coated onto the perovskite layer at $3500 \mathrm{rpm}$ for $30 \mathrm{~s}$. Finally, $100 \mathrm{~nm}$ gold electrode was deposited on the spiro-OMeTAD film by thermal evaporation.

\section{Device Characterization}

Transmission electron microscope (TEM) images were captured by Hitachi H-800 microscope at $200 \mathrm{kv}$ acceleration voltage. The time-resolved emission decay curves were measured by using time correlated single-photon counting (TCSPC) system of PLS980. The UV-vis absorption spectra and transmission spectra were examined using a UV-1800 spectrometer. Fourier transform infrared (FTIR) spectra were 
measured on a Bruker Equinox 70 spectrometer. The photoluminescence spectra were recorded by a FluoroSense luminescence spectrometer. The morphologies of the surface of perovskite, cross-sectional of PSCs and surface of dye connected UCNPs were all investigated by a A SIRION field-emission scanning electron microscope. The XRD patterns for $\mathrm{SnO}_{2}$ layer and $\mathrm{SnO}_{2} / \mathrm{UCL}$ composites layer were recorded by a Rigaku D/max $2550 \mathrm{X}$-ray diffractometer using a monochromatized $\mathrm{Cu}$ target radiation source from $20^{\circ}$ to $60^{\circ}$. The $\mathrm{J}-\mathrm{V}$ curves and steady output of current and PCE of the PSC devices were measured under 1 sun condition $\left(100 \mathrm{~mW} / \mathrm{cm}^{2}\right.$ AM $1.5 \mathrm{G})$ by using an ABET Sun 2000 solar simulator. The applied bias voltages were from -0.5 to $2.5 \mathrm{~V}$ (reverse scan) and 2.5 to $-0.5 \mathrm{~V}$ (forward scan). The incident photon conversion efficiency (IPCE) curves were obtained with a SolarCellScan100 measured system (Zolix Instruments, Inc.). Electrochemical impedance spectroscopy was performed on a Princeton electrochemical workstation (Parstat Mc Princeton Instruments Co. Ltd., USA) the applied bias voltage was set as $0 \mathrm{~V}$, and the frequency was from 0.1 to $10^{5} \mathrm{~Hz}$. Long term stability was measured unencapsulated, under dark in atmosphere with humidity of $30 \%$ to $40 \%$ and temperature of 20 to $25{ }^{\circ} \mathrm{C}$.

\section{Synthesis of core UCNPs with different particle sizes.}

Synthesis methods of $\mathrm{NaYF}_{4}: 20 \% \mathrm{Yb}, 2 \%$ Er nanocrystals coated with OA are as well-known method. ${ }^{1} \mathrm{YCl}_{3}(0.2367 \mathrm{~g}), \mathrm{YbCl}_{3}(0.0775 \mathrm{~g})$ and $\mathrm{ErCl}_{3}(0.0077 \mathrm{~g})$ are mixed with $\mathrm{OA}(6 \mathrm{ml})$ and $\mathrm{ODE}(15 \mathrm{ml})$ and heated to $150^{\circ} \mathrm{C}$ in a $100 \mathrm{ml}$ flask under $\mathrm{N}_{2}$ protection, and then cooled to $40^{\circ} \mathrm{C}$. $\mathrm{NaOH}(0.1 \mathrm{~g})$ and $\mathrm{NH}_{4} \mathrm{~F}(0.148 \mathrm{~g})$ fully dissolved in methanol solution $(6 \mathrm{ml})$ were slowly added to the flask. Subsequently, the solution was slowly heated to $120^{\circ} \mathrm{C}$ and kept for $30 \mathrm{~min}$ to evaporate the methanol, and then heated to $280-310^{\circ} \mathrm{C}$ for $1.5 \mathrm{~h}$. Finally, the product was washed by adding large amount of ethanol, centrifuged at $9000 \mathrm{rpm}$ for 20 minutes for 3 times, and dispersed in cyclohexane to prepare for the following experiments.

\section{Synthesis of core/shell UCNPs with different particle sizes.}

The synthesis step of $\mathrm{NaYF}_{4}: 20 \% \mathrm{Yb}$ and 2\% Er @ 20\% Yb, 20\% Nd is similar 
to that of the core $\mathrm{NaYF} 4 . \mathrm{YCl}_{3}(0.091 \mathrm{~g}), \mathrm{YbCl}_{3}(0.03875 \mathrm{~g})$ and $\mathrm{NdCl}_{3}(0.028 \mathrm{~g})$ are mixed with $\mathrm{OA}(6 \mathrm{ml})$ and $\mathrm{ODE}(15 \mathrm{ml})$ and heated to $150^{\circ} \mathrm{C}$ in a $100 \mathrm{ml}$ flask, and then cooled to $40^{\circ} \mathrm{C}$. The core $\mathrm{NaYF}_{4}$ dispersed in cyclohexane was slowly dripped into the flask and kept for 30 minutes. Then $\mathrm{NaOH}(0.05 \mathrm{~g})$ and $\mathrm{NH}_{4} \mathrm{~F}(0.0741 \mathrm{~g})$ fully dissolved in methanol solution $(6 \mathrm{ml})$ were slowly added to the flask. Subsequently, the solution was slowly heated to $120^{\circ} \mathrm{C}$ and kept for 30 min to evaporate the methanol and cyclohexane, and then heated to $280-310^{\circ} \mathrm{C}$ for $1.5 \mathrm{~h}$. Finally, the product was washed by adding large amount of ethanol, centrifuged at $9000 \mathrm{rpm}$ for 20 minutes for 3 times, and dispersed in cyclohexane to prepare for the following experiments.

\section{Synthesis of $\mathrm{NOBF}_{4}$ coated UCNPs}

The oleic acid ligand on the UCNPs surface was replaced by $\mathrm{NOBF}_{4}$ ligand by using the method described in the literature. ${ }^{2}$ The purpose is to convert the hydrophobic oleic acid-coated UCNPs into hydrophilic. Specific methods are as follows: first, $5 \mathrm{ml}$ oleic acid-coated UCNPs dispersed in cyclohexane $(10 \mathrm{mg} / \mathrm{ml})$ and mixed with $5 \mathrm{ml}$ of dissolved $\mathrm{NOBF}_{4}$ solution in DMF. The mixture was gently shaken for 10 minutes, and then the UCNPs moved from the upper cyclohexane to the lower DMF. Cyclohexane in the mixture was removed and the UCNPs by adding large amounts of toluene and cyclohexane for centrifuged at $9500 \mathrm{rpm}$ for 15 minutes. At last the $\mathrm{NOBF}_{4}$ coated UCNPs were dispersed in the DMF for further uses.

\section{Synthesis of dye sensitized UCNPs}

IR-783 dye was dissolved in DMF solution $(1 \mathrm{mg} / \mathrm{ml})$ for later use. $1 \mathrm{ml}$ of UCNPs DMF solution $(10 \mathrm{mg} / \mathrm{ml})$ was mixed with an appropriate amount of dye solution and kept at room temperature for 24 hours so that the dye could be attached to the surface of UCNPs, and then dye sensitized UCNPs was obtained.

\section{Synthesis of Au NRs}

Synthesis of Au NRs is adopted the method in the literature. ${ }^{3}$ The seed solution for $\mathrm{Au} \mathrm{NRs}$ growth was prepared as follows: $5 \mathrm{~mL}$ of $0.5 \mathrm{mM} \mathrm{HAuCl}{ }_{4}$ was mixed 
with $5 \mathrm{~mL}$ of $0.2 \mathrm{M} \mathrm{CTAB}$ solution in a $20 \mathrm{~mL}$ scintillation vial. $0.6 \mathrm{~mL}$ of fresh 0.01 $\mathrm{M} \mathrm{NaBH}_{4}$ was diluted to $1 \mathrm{~mL}$ with water and was then injected to the Au-CTAB solution under vigorous stirring (1200 rpm). The solution color changed from yellow to brownish yellow and the stirring was stopped after $2 \mathrm{~min}$. The seed solution was aged at room temperature for $30 \mathrm{~min}$ before use. To prepare the growth solution, $7.0 \mathrm{~g}$ in the final growth solution of CTAB and $1.234 \mathrm{~g} \mathrm{NaOL}$ were dissolved in $250 \mathrm{~mL}$ of warm water $\left(\sim 50{ }^{\circ} \mathrm{C}\right)$ in a $1 \mathrm{~L}$ Erlenmeyer flask. The solution was allowed to cool down to $30{ }^{\circ} \mathrm{C}$ and $24 \mathrm{ml} \mathrm{AgNO}_{3}$ solution was added. The mixture was kept undisturbed at $30{ }^{\circ} \mathrm{C}$ for $15 \mathrm{~min}$ after which $250 \mathrm{~mL}$ of $1 \mathrm{mM} \mathrm{HAuCl}_{4}$ solution was added. The solution became colorless after $90 \mathrm{~min}$ of stirring $(700 \mathrm{rpm})$ and $2.1 \mathrm{ml}$ of $\mathrm{HCl}(37$ wt. $\%$ in water, $12.1 \mathrm{M}$ ) was then introduced to adjust the $\mathrm{pH}$. After another 15 min of slow stirring at $400 \mathrm{rpm}, 1.25 \mathrm{~mL}$ of $0.064 \mathrm{M}$ ascorbic acid (AA) was added and the solution was vigorously stirred for 30 s. Finally, a small amount of seed solution was injected into the growth solution. The resultant mixture was stirred for $30 \mathrm{~s}$ and left undisturbed at $30^{\circ} \mathrm{C}$ for $12 \mathrm{~h}$ for $\mathrm{Au}$ NRs growth. The final products were isolated by centrifugation at $7000 \mathrm{rpm}$ for $30 \mathrm{~min}$ followed by removal of the supernatant.

\section{Reference:}

1. H.-X. Mai, Y.-W. Zhang, R. Si, Z.-G. Yan, L.-D. Sun, L.-P. You and C.-H. Yan, Journal Of the American Chemical Society, 2006, 128, 6426-6436.

2. A. Dong, X. Ye, J. Chen, Y. Kang, T. Gordon, J. M. Kikkawa and C. B. Murray, Journal Of the American Chemical Society, 2011, 133, 998-1006.

3. X. Ye, C. Zheng, J. Chen, Y. Gao and C. B. Murray, Nano letters, 2013, 13, 765-771. 